Etnográfica

Revista do Centro em Rede de Investigação em

Antropologia

vol. 24 (1) | 2020

Vol. $24(1)$

\title{
Redes de confiança, inserção e atuação profissional em partidos políticos no Brasil
}

Trusted networks, insertion and professional practice in political parties

\section{Wilson José Ferreira de Oliveira}

\section{(2) OpenEdition}

Journals

Edição electrónica

URL: https://journals.openedition.org/etnografica/9266

DOI: 10.4000/etnografica.9266

ISSN: 2182-2891

\section{Editora}

Centro em Rede de Investigação em Antropologia

\section{Edição impressa}

Data de publição: 1 fevereiro 2020

Paginação: 27-48

ISSN: 0873-6561

\section{Refêrencia eletrónica}

Wilson José Ferreira de Oliveira, «Redes de confiança, inserção e atuação profissional em partidos políticos no Brasil», Etnográfica [Online], vol. 24 (1) | 2020, posto online no dia 25 agosto 2020, consultado o 21 janeiro 2022. URL: http://journals.openedition.org/etnografica/9266 ; DOI: https:// doi.org/10.4000/etnografica.9266

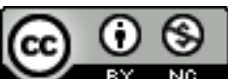

Etnográfica is licensed under a Creative Commons Attribution-NonCommercial 4.0 International License. 


\section{Redes de confiança, inserção e atuação profissional em partidos políticos no Brasil}

\section{Wilson José Ferreira de Oliveira}

As análises sobre os partidos políticos têm sido dominadas pela investigação dos candidatos e eleitos. Contrariando essa tendência, esse artigo focaliza os funcionários que ocupam cargos remunerados em diretórios de partidos políticos. A metodologia utilizada consistiu na realização de observação participante, questionários e entrevistas biográficas focando nas relações entre dinâmicas organizacionais, atributos sociais, relações pessoais e concepções de política vinculadas ao ingresso e à atuação profissional em partidos políticos. A pesquisa mostrou que variadas formas de relações pessoais constituem ingredientes fundamentais para o ingresso e a permanência em organizações partidárias, fazendo-se presentes em todos os partidos pesquisados, independente das siglas e orientações ideológicas.

PALAVRAS-CHAVE: etnografia política, relações pessoais, atuação profissional, partidos políticos.

Trusted networks, insertion and professional practice in political parties The analysis of political parties have been dominated by research about candidates and elected representatives. Contrary to this trend, this article focuses on employees who occupy paid positions in political parties' structures. Methodologically based on participant observation, surveys and biographical interviews focusing on the relations between organizational dynamics, social attributes, personal ties and political conceptions linked to the entry and the professional practice in political parties, research has shown that various forms of personal ties are very important for admission and continuity in political parties' structures, being present in all studied organizations, regardless of acronyms and ideological orientations.

KEYWORDS: political ethnography, personal ties, professional practice, political parties.

OLIVEIRA, Wilson José Ferreira de (etnografia.politica@gmail.com) - Departamento de Ciências Sociais (DCS), Laboratório de Estudos do Poder e da Política (LEPP), Universidade Federal de Sergipe (UFS), Brasil. 


\section{APRESENTAÇÃO}

As análises dos partidos políticos têm dado muita ênfase ao exame de suas relações com a democracia: o impacto de suas formas de estruturação e de mobilização, e seus apelos programáticos para a experiência democrática. ${ }^{1}$ Mesmo que se admita a existência de consideráveis diferenças na maneira como eles se organizam, de como mobilizam seus quadros e operam nas eleições e no parlamento, a ênfase sempre recai sobre seu papel como um dos "pré-requisitos" para a democracia (Katz e Crotty 2006; Dalton e Wattenberg 2000). Sem descartar a importância desse tipo de abordagem e preocupação, vale destacar que a mesma atenção não tem sido dada à apreensão da dimensão organizacional da atividade partidária: as condições e dinâmicas concretas de organização e funcionamento cotidiano e as lógicas práticas que operam na maneira como os profissionais trabalham e se relacionam com diversos grupos e ordens de atividade.

Chama a atenção o fato de que, mesmo os trabalhos vinculados ao Núcleo de Antropologia da Política (NuAP), o qual trouxe contribuições muito importantes para a consolidação dos estudos etnográficos da política no Brasil a partir dos anos de 1990, não tenham se interessado por esse tipo de objeto (Kuschnir 2007; Comerford e Bezerra 2013: 466). Como bem lembrou Camargo (2012), ainda que os partidos políticos sejam recorrentes em boa parte da produção e até mesmo façam parte das abordagens de grande parte das análises antropológicas da política, principalmente através dos trabalhos sobre eleições, eles nunca aparecem nesses estudos como objeto de investigação prioritário.

Esse desinteresse pela investigação das dinâmicas concretas de organização e de funcionamento cotidiano dos partidos políticos contribui para que a literatura que trata direta ou indiretamente da política partidária, tanto a internacional quanto a nacional, tenha se voltado prioritariamente para a investigação da profissionalização política a partir de candidatos e eleitos (Offerlé 1999; Dalton e Wattenberg 2000; Coradini 2001; Katz e Crotty 2006; Webb e Kolodny 2006; Grill 2008; Perissinotto e Miríade 2009; Gaxie 2012; Bolognesi 2013). Sem a pretensão de ser exaustivo, pode-se dizer que um traço comum dessas diferentes abordagens é que se parte, preferencialmente, dos percursos, trajetórias ou vínculos políticos, sociais e institucionais de candidatos ou eleitos para se estabelecer os fatos pertinentes e as explicações necessárias sobre a profissionalização política. É o caso dos trabalhos orientados por questões e problemas vinculados às perspectivas que se concentram na investigação do modo de operação das instituições partidárias, mas igualmente dos que priorizam a análise dos recursos, da estrutura de capital e das trajetórias dos agentes.

l A pesquisa que deu origem a esse trabalho foi financiada pela Capes, através do Procad NF 2009, pelo CNPq e pela Universidade Federal de Sergipe. 
No primeiro caso, a ênfase recai justamente sobre o "problema da seleção de candidatos", com o intuito de responder a questões como: Quem pode ser eleito? Quem escolhe? Quem é selecionado? Quais as consequências do recrutamento? (Norris 2013: 11; Braga e Bolognesi: 2013). Para responder a tais questões, o papel desempenhado pelos partidos políticos e os meios institucionais por eles utilizados ocupam um lugar decisivo, com destaque para estatutos, normas internas e programas, valores culturais e normas sociais referentes aos candidatos apropriados, tipos de experiências e conhecimentos adequados, modelando a oferta de candidatos, oferecendo redes sociais, treinamentos, habilidades cívicas e experiência organizacional (Norris 2013). Desse modo, tais trabalhos ressaltam a necessidade de dar a devida atenção à estrutura e à dinâmica prática do processo de escolha dos candidatos pelos partidos políticos, investigando o "grau de centralização", "amplitude da participação" e o "escopo do processo de tomada de decisão" referente aos candidatos selecionados (Norris 2013: 14).

No caso dos trabalhos que se centram nos agentes, em suas propriedades e trajetórias, trata-se, sempre, de apreender, com base em informações biográficas diversificadas sobre os candidatos e eleitos, suas propriedades sociais e deslocamentos no espaço social e político, ou a articulação destes elementos com mudanças e transformações diacrônicas (Coradini 2001; Grill 2008; Montalvão e Seidl 2010; Montalvão 2011; Gaxie 2012; Seidl e Grill 2013). Também nesse caso, as dinâmicas organizacionais e as lógicas práticas de funcionamento dos partidos políticos quase sempre aparecem como dimensões secundárias, não sendo analisadas em si mesmas nem recebendo uma atenção prioritária na investigação enquanto fonte de informação e de construção do próprio objeto de investigação.

Um dos principais efeitos dessa falta de interesse pelas dinâmicas práticas de organização e de funcionamento cotidiano das organizações partidárias é a persistência de uma grande lacuna na investigação, respeitante a um conjunto de funcionários e profissionais que desempenham atividades fundamentais, tanto para a conquista de cargos eletivos por parte dos candidatos, quanto para a permanência e continuidade das próprias organizações partidárias. Enquanto que muito se escreveu sobre ideologia, os membros e lideranças dos partidos, os padrões de recrutamento, atributos, perspectivas e carreira política dos candidatos e eleitos, campanhas, marketing, etc., pouco se sabe sobre essa categoria profissional.

"[...] relativamente pouco se sabe dos homens e mulheres que constam na folha de pagamento da organização e que dirigem de cima a baixo as operações cotidianas dos partidos nos países em que operam. Esta é uma falha significativa, o que nos deixa com uma compreensão deficiente de um aspecto importante do desenvolvimento da organização partidária" (Webb e Kolodny 2006: 337). 
Tal lacuna não parece condizente com um conjunto de estudos que já tem salientado, desde os anos de 1970, o quanto a propagação de partidos "eleitoreiros" (entenda-se: mais motivados por imperativos eleitorais do que ideológicos ou expressivos) conduziu à seleção de peritos em pesquisas, propaganda e marketing. Para isso, foram muito importantes os estudos quantitativos desenvolvidos na Europa, ao elucidarem o quanto esse efetivo aumenta no período eleitoral, como também o crescimento e a centralidade do conjunto dos funcionários pagos. Já nos EUA, a principal característica salientada tem sido o aumento e a imposição dos consultores políticos profissionais, como também de um conjunto de profissionais dos partidos financiados pelo governo para apoiar os eleitos oficiais, os membros do Congresso e do executivo: escritórios de imprensa e comunicação do governo, escritores de discursos, especialistas em relações midiáticas, etc. (Webb e Kolodny 2006).

Contrariamente a essa lacuna de estudos sobre os funcionários dos partidos políticos e à predominância de candidatos e eleitos nos estudos sobre a profissionalização política, a pesquisa que está na origem desse artigo procurou justamente examinar as dinâmicas de seleção e de atuação dos funcionários que ocupam cargos remunerados em diretórios nacionais, estaduais ou municipais de partidos políticos no estado de Sergipe. Tal estado é o menor dos estados brasileiros, ocupando uma área total de $21.915,116 \mathrm{~km}^{2}$, e sua população em 2018 foi recenseada em 2.278.308 habitantes. Está situado na região Nordeste e tem por limites o oceano Atlântico, a leste, o estado da Bahia, a oeste e a sul, e o de Alagoas, a norte, do qual está separado pelo rio São Francisco.

Em Sergipe, semelhante ao que se tem salientado a respeito do sistema político nacional, os laços pessoais estabelecidos com amigos, conhecidos ou políticos constituem uma das principais condições para o ingresso e a permanência dos militantes, funcionários e dirigentes em tais organizações (Rocha 2009; Camargo 2012). Tal aspecto está estreitamente ligado ao peso dos laços, vínculos, alianças e relações pessoais que extrapolam o domínio estritamente "familiar" entre os principais grupos políticos dominantes no estado, e às dinâmicas de emergência e de consolidação dos partidos políticos no estado (Dantas 2002, 2004; Petrarca e Oliveira 2016, 2017). Também tem uma importância fundamental para a compreensão das lógicas contextuais e locais de implantação dos principais grupos políticos do estado e do papel das alianças eleitorais na transformação das organizações e práticas partidárias no Brasil (Dantas 2002, 2004; Goirand 2007; Oliveira 2015b).

Aqui reside outro aspecto que não tem recebido a merecida atenção das ciências sociais. Mesmo que, atualmente, não constituam mais uma novidade, os trabalhos que evidenciam a influência dos círculos sociais imediatos nos quais as pessoas vivem sobre suas crenças e práticas políticas, as ciências sociais, e em especial a ciência política, têm demonstrado uma "relação complexa" com esses tipos de estudos (Zuckerman 2005b: 3). Por isso, de forma surpreendente, 
predominaram durante muito tempo as interpretações dessas relações em termos moralizantes e normativos, de modo que a identificação de sua presença nas instituições políticas e no funcionamento das organizações partidárias e dos processos eleitorais era definida como sobrevivência de práticas tradicionais e indicador de fraca relação institucional (Bezerra e Oliveira 2015; Petrarca e Oliveira 2017). Como resultado disso, são raros os trabalhos que se debruçam concretamente sobre as relações pessoais no âmbito da estruturação e do funcionamento cotidiano da política, e dos partidos políticos em particular (Webb e Kolodny 2006).

Recentemente, esse quadro parece ter se modificado, na medida em que encontramos uma série de estudos que demonstram a importância das relações pessoais, familiares, de amizade, das obrigações morais e dos sentimentos de gratidão, entre outros, como elementos constitutivos do comportamento político e das práticas eleitorais, da domesticação do Estado e da administração pública, do recrutamento e da continuidade da atuação em organizações e movimentos sociais (McAdam e Paulsen 1993; Passy 1998; Auyero 1999; Fillieule 2001; Zuckerman 2005a; Verba, Schlozman e Burns 2005; Combes 2009; Combes e Vommaro 2012; Auyero 2013; Diani e McAdam 2003; Bezerra 2017; Briquet 2017). Tais perspectivas têm contribuído para a ruptura com as análises que definem as relações pessoais como antagônicas e excludentes dos vínculos e práticas institucionais, possibilitando levar em conta as combinações, sobreposições e tensões entre as relações e práticas políticas vinculadas a esses distintos princípios de dominação (Oliveira 2015a; Petrarca e Oliveira 2017). Nesse sentido, um dos principais desafios colocados atualmente à análise da política partidária consiste em apreender como os laços, vínculos e relações pessoais que aparecem na base da organização e do funcionamento dos partidos políticos estão de alguma forma associados à maior centralidade adquirida pelos partidos políticos no processo eleitoral brasileiro, à importância das relações com os órgãos da justiça eleitoral e ao peso das exigências e regulações na constituição de profissionais que desempenham um papel central na contabilidade e registro das candidaturas (Camargo 2012).

Para dar conta de tais questões, a metodologia utilizada na investigação que deu origem a esse artigo consistiu, primeiramente, no levantamento dos diretórios estaduais dos 28 partidos existentes no estado e dos nomes de seus principais dirigentes nos sites do Tribunal Regional Eleitoral e do Tribunal Superior Eleitoral. Num segundo momento, visitamos 16 diretórios onde realizamos observação direta e, após isso, aplicamos 32 questionários junto de funcionários e dirigentes de 19 dos 20 partidos existentes em Sergipe: em seus diretórios, em suas residências, escritórios, ou nas instituições de ensino onde estudam. Tais questionários possibilitaram apreender os critérios de recrutamento para a ocupação de cargos dirigentes e empregatícios nestas instituições e traçar um perfil social dos que ocupam tais posições. Após o trabalho de observação do cotidiano partidário nos diretórios, selecionamos e negociamos 
a realização de entrevistas etnográficas com profissionais dos diretórios, com o intuito de aprofundar os vínculos e relações que os conduziram ao referido cargo, assim como as concepções de sociedade e política que fundamentam sua inserção e sua permanência nas organizações partidárias.

\section{AS RELAÇÕES PESSOAIS E AS REDES DE CONFIANÇA COMO FORMA DE ACESSO E INSERÇÃO NO PARTIDO}

Nos repetidos encontros durante o processo de negociação da observação, aplicação dos questionários e realização das entrevistas, pudemos observar certa diferenciação quanto às formas de tratamento e de aceitação de nosso acesso aos partidos: de um lado, os que nos viam com certa desconfiança e até mesmo com o que poderíamos inicialmente chamar de "medo"; de outro lado, os que se mostravam prontamente sem reservas e que nos acolhiam com solicitude.

O tratamento sem reservas esteve associado a certo "conhecimento" ou contato prévio do entrevistado com as ciências sociais, com o coordenador da pesquisa, com o entrevistador ou mesmo com amigos e colegas de curso. Nessa disposição se deu o contato com os partidos cujos entrevistados fazem ciências sociais e já tinham sido alunos do coordenador da pesquisa, colegas de curso do entrevistador ou amigos desses, bem como partidos nos quais, além dos aspectos anteriores, a presença de membros e militantes vinculados às ciências sociais é muito frequente (Partido dos Trabalhadores, PT; Partido Socialista dos Trabalhadores Unificado, PSTU; Partido Socialismo e Liberdade, PSOL; Partido Comunista do Brasil, PCdoB). Outra situação que facilitou o acesso e a disponibilidade dos entrevistados para a pesquisa foi o fato de serem "conterrâneos" do entrevistador. Tal situação facilitava o estabelecimento do contato, bem como certa descontração durante a conversa inicial, uma vez que dava acesso a acontecimentos, nomes de pessoas, lideranças e fatos políticos locais.

Já a atitude desconfiada, com reservas ou desinteressada está associada às situações nas quais os entrevistados desconhecem o entrevistador, o coordenador da pesquisa e colegas do curso de ciências sociais ou, no limite, quando demonstram certo conhecimento das ciências sociais ou as vinculam a determinados partidos, como PT, PSOL ou PSTU. Uma situação ilustrativa disso foi um dos primeiros contatos com o diretório dos Democratas (DEM). Ao apresentar a pesquisa como vinculada à Universidade Federal de Sergipe (UFS) e com o tema dos partidos políticos, a atendente demonstrou certo medo e disse "que não tinha nada a ver com essas coisas", sugerindo que falássemos com outro funcionário, o qual indagou novamente quem era o entrevistador e sobre o objetivo da pesquisa. Situação semelhante ocorreu no Diretório Estadual do Partido Democrático Trabalhista (PDT), onde uma senhora, quando foi informada que o questionário visava coletar informações sobre funcionários dos partidos, ficou assustada e apreensiva, dizendo imediatamente que não era 
funcionária. Situações semelhantes ocorreram no Partido Social Liberal (PSL), Partido Socialista Cristão (PSC), entre outros.

Essas diferenças quanto às formas de relacionamento com os pesquisadores e os objetivos da pesquisa podem ser mais bem consideradas quando se observa que as demandas por filiação que os entrevistados dirigiam aos pesquisadores não provinham de igual maneira do conjunto dos partidos contatados. Pelo contrário, no primeiro conjunto de partidos com os quais os pesquisadores tinham algum tipo de "proximidade", como descrito acima, isso nunca ocorreu. Em nenhum momento nos sentimos desconcertados e até mesmo constrangidos com indagações sobre em quem iríamos votar ou qual era nosso partido. No entanto, com os partidos com os quais tínhamos um maior "distanciamento" era muito comum sermos "presenteados" com adesivos, cartilhas, livretos e estatutos e com convites para a filiação. Outras situações mais constrangedoras ocorriam quando, no início da conversa, após expormos os objetivos da pesquisa, ouvíamos o entrevistado nos perguntar se votaríamos em seu candidato.

Porque certos contatos eram tão fáceis e amigáveis e outros tão tensos e cheios de desconfiança? Porque em certos partidos éramos publicamente constrangidos a responder a perguntas sobre nossas opções eleitorais, enquanto que em outros partidos tais questões jamais vinham à tona? Até que ponto essas e questões similares que surgiram em função do processo de pesquisa já nos diziam algo sobre o modo de configuração da própria realidade social a ser investigada? Aos poucos, e principalmente no caso daqueles partidos que se mostravam mais distantes e de difícil acesso, percebemos que o fato de ir ostensivamente a um mesmo diretório e o estabelecimento de conversas constantes sobre familiares, parentes e conhecidos, e mesmo sobre questões pessoais, possibilitaram a criação de uma relação de confiança com alguns funcionários e dirigentes de tais partidos. Isso facilitou o acesso à pesquisa e, em alguns casos, uma mudança da sensação inicial de desconfiança para uma atitude de maior descontração e solicitude.

Não é de hoje que se tem demonstrado o quanto "o laço pessoal" com pessoas que mantêm vínculos institucionais com o universo de pesquisa constitui um dos recursos principais para o acesso do pesquisador ao terreno de investigação. Tal como nas situações comuns ou no dia a dia do funcionamento institucional, tais relações têm um peso bem maior do que as "referências institucionais e formais": chamar a atenção para a "particularidade" de nossa situação, encontrar alguém que se faça de "porta-voz" de nossos interesses, utilizar "argumentos" e "tratamentos" pessoais, etc., constituem recursos bem mais eficazes para o ingresso e a obtenção de material relevante para a pesquisa, do que recorrer a obrigações e argumentos formais e institucionais (Bezerra 1995: 26-28).

Nesse sentido, essa dificuldade própria do processo de acesso ao terreno e ao material de investigação nos colocou diante de um dos aspectos mais 
constantes dos modos de operar dos partidos políticos e, particularmente, das formas de seleção dos que ocupam cargos remunerados em tais organizações, independente das siglas e ideologias partidárias: a importância dos vínculos pessoais com amigos, conhecidos, parentes, etc., para o ingresso em tais organizações. Assim, observamos que, em 28 questionários (dos 32 aplicados), um percentual de $78,6 \%$ reconhece a importância da indicação de amigos, conhecidos ou políticos na escolha do partido onde trabalha. Enquanto isso, os que consideram que tais tipos de vínculos tiveram pouca importância para o acesso ao cargo que ocupam no partido constituem um percentual de $21,4 \%$. De forma semelhante, o conhecimento prévio de colegas que eram da mesma área e atuavam já na instituição partidária também tem um peso relevante, alcançando um percentual de 64,4\%.

Sem dúvida, um dos primeiros desafios na análise de tal objeto consistiu justamente em "levar a sério" o próprio processo de aplicação de questionários e de realização de entrevistas e as respectivas informações que nos eram constantemente reveladas, na medida em que são formas de "deixar falar o objeto" e que precisam ser seguidas para que possamos constituir, sob o concreto, os atores, os lugares e as temporalidades próprias desse objeto (Favre, Fillieule e Jobarb 2007). Nesse sentido, as negociações para o acesso ao terreno de investigação, com suas surpresas e inquietações, nos colocaram em contato direto com os modos de operar dos partidos, com as concepções e práticas inculcadas pelos seus membros e funcionários, em suma, com relações constitutivas do universo que estávamos querendo pesquisar.

Tais indagações evidenciaram, por um lado, a pertinência das relações pessoais como forma de acesso do pesquisador ao universo de pesquisa, reforçando a importância do estabelecimento de uma "relação de confiança" (Beaud e Weber 1998) e de realização de um verdadeiro trabalho, por vezes longo e paciente, de "confecção das redes de confiança" (Bennani-Chraïbi 2010). Ao mesmo tempo, nos colocaram diante da enorme dificuldade de acesso à observação direta e cotidiana dos partidos políticos. Merece uma reflexão mais aprofundada o fato de que seja justamente em função do imenso e demorado trabalho de "confecção das redes de confiança" que esse tipo de investigação envolve que ainda sejam escassos os estudos com base na observação direta e de longa duração das organizações partidárias e que grande parte da literatura se dedique ao seu estudo com base apenas nos candidatos e eleitos.

\section{OS LAÇOS COM OS DIRIGENTES PARTIDÁRIOS E A ATUAÇÃO PROFISSIONAL NAS ORGANIZAÇÕES}

A necessidade de constituição das "redes de confiança" para o acesso ao campo de pesquisa e a recorrência dos "laços pessoais" como forma de ingresso na política partidária não constituem os únicos aspectos que os partidos políticos 
expõem durante o processo de negociação do acesso às fontes de informação. Em muitos casos, o difícil acesso aos funcionários das organizações partidárias está diretamente ligado à própria dinâmica de funcionamento dos partidos e sua relação com o período eleitoral. O impacto das eleições sobre a organização e a dinâmica de funcionamento cotidiano do conjunto dos partidos políticos nos colocou diante de um universo bastante heterogêneo e diferenciado em termos das funções empregatícias neles exercidas: num extremo, encontramos uma boa estrutura organizacional e um quadro permanente de funcionários contratados; no outro, partidos desprovidos de condições mínimas para a manutenção de seu funcionamento cotidiano e de forma permanente, como sede, secretária, secretário executivo, etc.

Se os partidos são tidos como um dos principais fatores para o funcionamento da política como uma atividade permanente (Weber 1979; Michels 1982; Phélippeau 2001), eles aparecem, de fato, como diretamente dependentes das temporalidades da política eleitoral. Por isso, tanto o período imediatamente próximo às eleições quanto o muito distante delas constituem momentos de difícil acesso ao universo pesquisado: no primeiro caso, pelo excesso de atividades envolvendo os funcionários dos partidos; no segundo, pela inexistência de local para atendimento, em alguns casos, uma vez que a organização somente dispõe de sede e pessoal permanente nos diretórios no período eleitoral. Em alguns casos, são recorrentes certas funções como secretário-geral, auxiliar administrativo, tesoureiro, enquanto que, em outros, tais atribuições são exercidas pelos próprios presidentes.

Por isso, se nossa pretensão, desde o início, era não limitar a investigação aos chamados políticos profissionais, em algumas situações isso foi praticamente impossível. Em nosso universo de entrevistados, 28, 1\% dos que exercem funções administrativas são dirigentes, não dispondo o partido de nenhum funcionário contratado. Encontramos também uma quantidade enorme de profissionais que atuam nos partidos, mas que são cedidos de outras instituições vinculadas à política do referido partido (21,9\%): funcionários públicos da prefeitura, da assembleia e do governo estadual, do senado federal, assessores parlamentares que prestam serviços ao partido, detentores de cargos de confiança, etc. Assim, apenas 37,5\% dos entrevistados são funcionários cujo vínculo com o partido é de efetivo contratado. Essa heterogeneidade quanto aos tipos de vínculos empregatícios com o partido se desdobra na combinação da função empregatícia exercida nele com outras funções na estrutura partidária e até mesmo em outras instituições.

Quanto a isso, a investigação demonstrou que, tanto no estado de Sergipe quanto no restante do Brasil, o valor da arrecadação do Fundo Especial de Assistência Financeira aos Partidos Políticos (fundo partidário), administrado pelo Tribunal Superior Eleitoral (TSE) e que se destina à manutenção dos partidos políticos, constitui um aspecto importante para a compreensão dessa 
diferenciação em termos das dinâmicas organizacionais, em termos, por exemplo, da manutenção de sedes, da existência e tamanho do quadro funcional com cargos remunerados, da aquisição de equipamentos eletrônicos (principalmente computadores), etc.

Isso porque, oficialmente, uma das principais fontes de receita dos partidos políticos é justamente a oriunda do repasse das cotas do fundo partidário, previsto no artigo $17 .^{\circ}$, § $3 .^{\circ}$, da Constituição Federal, o qual é constituído pela arrecadação de multas eleitorais, doações de pessoas físicas ou jurídicas e dotações orçamentárias da União. O Tribunal Superior Eleitoral é incumbido de fazer a respectiva distribuição aos órgãos nacionais dos partidos, obedecendo aos seguintes critérios: 5\% do total do fundo partidário são destacados para entrega, em partes iguais, a todos os partidos que tenham seus estatutos registrados no Tribunal Superior Eleitoral e 95\% são distribuídos aos partidos que tenham direito a funcionamento parlamentar, na proporção dos votos obtidos na última eleição para a Câmara dos Deputados. Os órgãos nacionais dos partidos políticos procederão à redistribuição da cota recebida às seções regionais, e estas às municipais, na forma disposta pelos respectivos estatutos, e a sua movimentação deve ser feita em estabelecimentos bancários oficiais. Os recursos provenientes do fundo partidário devem ser aplicados na manutenção das sedes do partido, no pagamento de pessoal, na propaganda política, nas campanhas eleitorais, na criação e manutenção de instituto ou fundação de doutrinação e educação política e em programas de promoção e difusão da participação política das mulheres.

Observa-se que 39,11\% do total do fundo partidário no ano de 2013 estavam concentrados em apenas três partidos: o PT com 16,09\%, o PMDB com $12,01 \%$, e o PSDB com $11,01 \%$. Outro conjunto formado por cinco partidos tinha uma participação de $31,41 \%$ do total: o PR com 7,01\%, o PP com 6,72\%, o PSB com 6,68\%, o DEM com 5,01\% e o PSD com 3,66\%. Somando-se esses dois conjuntos, pode-se dizer que oito partidos, do total de 32 , concentram $70,52 \%$ do total destinado aos partidos políticos. Encontramos ainda um percentual de $22,94 \%$ distribuídos em oito partidos dos 24 restantes, os quais contam com uma participação no fundo variando entre $1,82 \%$ e $4,74 \%$. Por fim, 16 partidos ficam com percentuais individuais abaixo de $1 \%$, totalizando no total 6,54\% de participação no fundo partidário. ${ }^{2}$

Em consonância com isso, o Partido dos Trabalhadores (PT) era um dos poucos que possuía em Aracaju dois diretórios, um estadual e um municipal, existindo no primeiro três funcionários (auxiliar administrativo, assessor financeiro e secretário executivo) e, no segundo, apenas um. Não por acaso,

2 Dados do Tribunal Superior Eleitoral, em "Distribuição do Fundo Partidário 2013 - Duodécimos", disponível em < http://www.justicaeleitoral.jus.br/arquivos/tse-distribuicao-do-fundo-partidario-duode cimos-2013 > (última consulta em fevereiro de 2020). 
tratava-se do partido que naquele momento figurava como o primeiro no ranking da arrecadação do fundo partidário. Algo semelhante ocorria com os outros partidos que também figuravam entre os primeiros na arrecadação do fundo partidário (PMDB, PSDB, DEM, PSB) e que contavam com os recursos advindos dele para a manutenção das sedes e o pagamento dos funcionários. No outro extremo, entre os partidos que tinham uma pequena arrecadação do fundo partidário (PSTU, PSOL, etc.), os relatos eram de que havia enormes dificuldades para que seus partidos possuíssem um quadro funcional com cargos remunerados, bem como os recursos para a manutenção de seus diretórios.

Assim, a existência de funcionários com carga horária e funções específicas, ainda que diversificadas, apresentava-se, inicialmente, estreitamente ligada à participação do partido na arrecadação do fundo partidário, pois os partidos onde eram recorrentes algumas funções, como secretário-executivo, auxiliar administrativo, tesoureiro, etc., eram justamente os que tinham uma participação maior nesse fundo, enquanto que, nos que dispunham de uma parcela muito pequena de tais recursos, era comum encontrarmos os dirigentes desempenhando ou acumulando estas funções, bem como a utilização de profissionais licenciados ou cedidos de outras instituições para as desempenhar.

Todavia, em meio a essa enorme variedade em termos de estrutura organizacional, de vínculos e exercício de funções empregatícias nos partidos, o conjunto dos entrevistados apresenta algumas características gerais que merecem ser destacadas. Trata-se de uma população com faixas etárias predominantemente acima dos 32 anos (81,2\%). Ou seja, apenas 18,8\% do total estão na faixa etária que fica entre 22 e 31 anos, enquanto que $68,7 \%$ estão na faixa que vai dos 32 aos 52 anos e 12,5\% estão acima de 52 anos. Assim, pode-se dizer que não se trata de um conjunto cujo ingresso no partido é concomitante ou imediatamente posterior à entrada no mercado de trabalho, seja após a conclusão de seus estudos secundários ou mesmo universitários. Até mesmo porque dos 18 questionários que apresentam informações sobre o grau de escolarização, somente um percentual de 33,3\% possui formação universitária completa, enquanto que 55,6\% possuem apenas formação secundária completa. Num total de 32 questionários, 87,5\% exerceram atividades profissionais anteriormente à ocupação do atual cargo no partido, enquanto que apenas $12,5 \%$ não exerceram atividades profissionais.

Essa forte articulação da formação escolar e universitária com a militância política não parece caracterizar a entrada no partido do conjunto investigado. Até mesmo porque, para o conjunto, a militância anterior em organizações estudantis, sindicais, religiosas, profissionais ou em associações de bairros e movimentos sociais é, em geral, muito reduzida, não ultrapassando o percentual de $20 \%$. Pelo contrário, é muito alto o percentual dos que nunca participaram nem participam de movimentos sociais (81,3\%), organizações profissionais $(81,3 \%)$, associações de bairro $(78,1 \%)$, sindicatos $(75 \%)$, organizações 
estudantis (71,9\%). Mesmo a militância anterior em partidos políticos ou na própria organização em que trabalha é muito pequena, com um percentual de $12,5 \%$.

Isso não impede que, quando se trata da participação em partidos políticos, um percentual de $46,9 \%$ diga respeito aos que têm nessa forma de organização seu primeiro engajamento político. Ao que tudo indica, isso ocorre porque tal engajamento e mesmo filiação é geralmente posterior ao ingresso no partido como funcionário e constitui uma forma de consolidação dos laços pessoais anteriormente estabelecidos com amigos, conhecidos ou políticos que os indicaram à ocupação do referido cargo. Como comprovação disso, está o percentual de $84,4 \%$ para os que são filiados ao partido em que integram o quadro funcional. Considerando a militância partidária como atividade que diz respeito a "atores, que além do fato de se filiarem, desenvolvem ou ao menos desenvolveram um mínimo de participação em termos de atividades partidárias, seja enquanto militante de base, seja como liderança" (Rocha 2009: 72), pode-se dizer que se trata de um universo de forte militância política. No entanto, mais do que algo que antecede o ingresso no partido, esse engajamento e militância só se desenvolve e se consolida a partir do ingresso e da permanência na organização partidária.

Todavia, mais importantes do que qualquer atributo em particular, e até mesmo de certa bagagem profissional e de militância anterior, são as relações pessoais que se apresentam como um fator essencial para o ingresso e os tipos de investimento nas organizações partidárias, corroborando achados de outros estudos sobre o tema que demonstram que a maioria deles constrói uma relação direta e pessoalizada com dirigentes locais do partido (Goirand 2007; Rocha 2009). Variadas formas de relações e de vínculos pessoais constituem ingredientes fundamentais para o ingresso e a permanência em organizações partidárias, fazendo-se presente em todos os partidos pesquisados, independente das siglas e orientações ideológicas, mesmo que em alguns casos elas decorram de socialização em organizações, movimentos e grupos militantes. Tais formas de ingresso estão associadas a concepções da atividade no partido como boa gestão de relações pessoais e afetivas. Assim, em meio a um conjunto muito diversificado de posições e de cargos ocupados como funcionários nos partidos políticos, os investimentos pessoais, políticos e profissionais dos funcionários nas organizações partidárias podem ser apresentados sob a forma de três figuras principais: a do "seguidor", a do "militante" e a do "funcionário".

A figura do "seguidor" caracteriza-se por uma forte vinculação ao presidente do partido. Nessa situação, o vínculo pessoal de longa data com o dirigente do partido constitui a tônica principal, resultando em concepções que têm na relação de confiança a base principal da ocupação do cargo. Um exemplo bastante típico disso é o caso de um técnico em contabilidade, que deixou o emprego como auxiliar administrativo e exerce como cargo de confiança a 
função de secretário executivo do partido, atuando nessa área há aproximadamente 35 anos. Ele é filho de comerciantes com baixa escolaridade, de nível por ele próprio definido como de "alfabetizados", mas que não tinham engajamento político, embora tenha parentes que "já foram prefeitos”. Mesmo já tendo participado de movimentos sociais, seu primeiro engajamento foi num partido político, justamente em função do ingresso como técnico em contabilidade do partido. Todavia, seu ingresso nesse tipo de atividade teve como base suas amizades e a "necessidade". Pessoa de "confiança" do presidente do partido, é a relação de "confiança" existente entre eles, desde longa data, aproximadamente 35 anos, que está na base da função que desempenha no partido, que o mantém no cargo e que o conduz à ocupação de tal função em diferentes cargos de vários partidos por onde já passou. Como ele mesmo relatou, "Na verdade eu sou o secretário dele", "Onde ele estiver ele me leva", "Trabalho com ele vai fazer 35 anos... Então, para o partido que ele for, eu vou”. De forma recíproca, o mesmo lhe disse: "Preciso de alguém para tomar conta do partido [...] Olhe! Você vai comigo". Dessa forma, ele já passou por todos os partidos em que o presidente ingressou, tendo ocupado os mais variados cargos nas executivas destes - secretário do presidente do partido, assessor parlamentar especial, tesoureiro, etc.

"Rapaz! O que me mantém no cargo é a confiança do presidente aqui dentro. Eu trabalho porque fico sempre disposto 24 horas. Na hora que ele liga, pode ser feriado, um sábado, um domingo à noite, eu estou sempre... Agora mesmo eu estou começando a fazer a transmissão da televisão, então eu tenho que ficar ligado 24 horas".

A figura do "militante" toma alguns contornos diferenciados da do "seguidor" do chefe de partido. O principal deles é que, nesse caso, mesmo que os vínculos pessoais com dirigentes do partido constituam a base de seu ingresso e permanência no partido, tais vínculos resultam da inserção comum em organizações políticas e movimentos sociais e estão fundados em concepções de que a atuação política no interior do partido é um ingrediente importante do exercício de sua função. Como consequência disso, nessa forma de atuação profissional, o envolvimento com a "parte política” é bem maior do que o dos "seguidores". Um exemplo típico disso é o caso de um secretário executivo de diretório estadual que ocupa tal cargo desde 2006 e é formado em gestão (tecnologia da informação). Ele nasceu e morou todo o tempo no bairro América, que era um dos bairros da periferia de Aracaju e muito estigmatizado pela presença da violência e de drogas. Seu pai tinha o ensino médio completo e era funcionário público, já sua mãe tinha o ensino superior completo e era professora de um colégio público, de modo que foi com base em seu vínculo de funcionária que conseguiu uma bolsa para o filho estudar lá. O fato de viver 
num bairro que era estigmatizado, a ponto de muitos vizinhos terem vergonha de dizer que moravam nele, e de estudar num colégio de classe média o levou desde cedo a sentir certa discriminação por ser negro e morar em tal bairro. No entanto, foi somente quando iniciou o curso de engenharia química na Universidade Federal de Sergipe que, segundo ele próprio, teve a “a oportunidade de ficar mais à vontade" e iniciou o percurso que fez com que ele parasse em tal cargo. Isso porque foi nesse período que iniciou a militância no movimento estudantil e começou a trabalhar na iniciação científica com um professor que tinha sido presidente do DCE, depois foi pró-reitor e, mais tarde, veio a ser superintendente do Ibama (Instituto Brasileiro do Meio Ambiente e Recursos Naturais Renováveis) e presidente do partido. Foi pelo vínculo estabelecido com esse professor que ingressou no partido: primeiramente como estagiário do Ibama, depois como secretário do partido, quando aquele tornou-se presidente do partido estadual. É com base nisso que ele afirma que foi "através da mão dele mesmo" que "vim parar aqui". Tal itinerário está associado a uma concepção militante do exercício do cargo, em que, para ele, funciona como uma espécie de "consultor" que ouve as angústias, os reclamos e os desabafos vivenciados nos municípios e faz a interlocução com as metas e as regras estabelecidas pela direção.

"Porque eu sou, digo sempre, mais militante do que funcionário, eu acho que não tem como descasar as duas coisas. Até tem! Porque existem outras instituições que têm funcionários daqui e não têm uma relação militante, então eu sou militante que saiu lá do movimento estudantil, sou mais militante do que funcionário."

Por fim, na figura do "funcionário", tanto a relação com o chefe de partido quanto com a militância são bastante diferenciadas das duas anteriores. Essa situação, ainda que os vínculos pessoais constituam também o meio de ingresso no partido, não desemboca numa forte vinculação e até mesmo dependência em relação ao dirigente que colocou o profissional no partido. Por outro lado, o distanciamento em relação à militância em organizações e movimentos sociais conduz a uma concepção do exercício do cargo no partido como uma função distanciada e bem separada do envolvimento com ideologias, opções e atuações políticas. Um exemplo disso é o caso de um assessor político de um diretório estadual que trabalha no partido desde 2003. Ele nasceu no Rio de Janeiro, mas sua mãe era de Aracaju. Aos três meses ficou órfão de mãe e foi, junto com a irmã, morar com os avós maternos em Aracaju. Seu avô materno era ex-combatente da Marinha e retornou a Aracaju após aposentar-se. Durante sua formação escolar, nunca participou de grêmio estudantil e o que mais recorda como marcante do científico foi o gosto pela matemática que, segundo ele, teve um papel decisivo em sua formação. Em 2012 concluiu o curso de tecnólogo 
em gastronomia pela faculdade Serigy, que, segundo ele próprio, "não tem nada a ver com partido político [risos]". No entanto, foi através de seu primo, que era e ainda é um dos principais dirigentes do partido, que ingressou em tal cargo, em decorrência de ter surgido uma vaga. Todavia, isso não desembocou num maior envolvimento com a militância política e partidária. Pelo contrário, é certo distanciamento entre o que faz como funcionário e as exigências da política partidária que fundamenta o exercício de seu cargo.

"Uma coisa é você ser funcionário e outra coisa é você ser político do meio, então uma coisa não tem nada a ver com a outra. Então, talvez por isso o serviço flua melhor você não sendo político e você sendo técnico. Que tem pessoas que não sabem diferenciar. [...] Não sou militante, não sou político, minha amizade não é de político, minhas amizades não são de políticos - pode até ser que surja, mas essas pessoas não são políticas, elas trabalham com política. [...] Não tenho amigo deputado, vereador, senador, não são meus amigos".

Independente das legendas partidárias e dos diferentes grupos políticos vinculados às organizações partidárias, um aspecto recorrente na análise das formas de ingresso dos funcionários é que todos têm acesso a tal cargo a partir de laços e vínculos pessoais com dirigentes do partido, sejam laços diretos (com o próprio dirigente ou lideranças do partido) ou indiretos (com parentes, amigos, colegas que têm vínculos mais fortes com determinado dirigente). No entanto, apesar dessa linha de continuidade dos laços pessoais como forma de ingresso no partido, há uma clara diferença entre os funcionários quanto às concepções do exercício do cargo e de sua atuação nos partidos políticos. Enquanto que, para alguns, o partido e o cargo resultam da manutenção e reafirmação de fortes vínculos estabelecidos com determinado dirigente, para outros, tal atuação se combina com uma intensificação do engajamento e da militância política anterior que, como eles próprios dizem, são essenciais para se manter e continuar exercendo suas funções nos partidos. Já para outros ainda, sua atuação não ultrapassa a agenda profissional de entrega de documentos para abertura de alguma campanha ou qualquer outra função e ocorre mediante certo distanciamento das atividades e atuação político-partidária.

Como podemos ver, apesar da importância destacada dos laços e vínculos pessoais como forma de ingresso nas organizações partidárias, eles não parecem suficientes para dar conta da enorme variação que observamos nas formas de atuação profissional dos funcionários. Isso porque tais formas de atuação estão diferentemente combinadas com inserções anteriores em organizações e movimentos sociais e com tipos distintos de experiências profissionais. Nesse sentido, quanto mais o vínculo pessoal esteja dissociado de inserções e experiências em outras organizações e universos sociais, maior será o peso dele para 
a atuação profissional como funcionário. Quando combinado com outros tipos de recursos e experiências profissionais, o peso do vínculo pessoal para a atuação profissional parece ser menos determinante.

Além disso, estas diferentes formas de atuação não ocorrem num vazio institucional, uma vez que estão também associadas às dinâmicas de organização e de funcionamento dos próprios partidos políticos. Nesse sentido, é naqueles partidos mais centrados nos líderes, e até mesmo num líder "único", e que apresentam baixa ou nenhuma "participação de instâncias intermediárias" na seleção de candidatos, que o peso dos laços pessoais adquire maior relevância na forma de atuação do funcionário; naqueles casos em que a presença de "líderes intermediários" é maior e nos quais a seleção dos candidatos realiza-se mediante instâncias intermediárias e de base, é mais comum observarmos um tipo de atuação profissional fortemente combinada com inserções em outros tipos de organizações e movimentos sociais (Bolognesi 2013).

Sem dúvida, tais variações e combinações são extremamente importantes, pois nos mostram a pertinência de sempre examinar de forma relacional as condições organizacionais e burocráticas, os laços e relações pessoais e as inserções dos indivíduos no decorrer de seus percursos políticos e profissionais. Tal perspectiva constitui um passo importante para a ruptura com análises exclusivamente centradas na demonstração do peso excessivo das condições e lógicas institucionais ou burocráticas, por um lado, ou nas relações e laços sociais estabelecidos ao longo das trajetórias individuais, por outro (Petrarca e Oliveira 2017).

\section{CONCLUSÕES}

Não é de hoje que a falta de interesse em descobrir a "racionalidade" e a "linha de continuidade" internas da política brasileira tem sido apontada como responsável nas análises que veem essa política como "caótica", "absurda" e "irracional" (Queiroz 1976: 29). Nos últimos anos tem persistido e até mesmo se expandido tal atitude, apesar da grande renovação e diversificação teórica, conceitual e metodológica dos estudos sobre os fenômenos políticos no Brasil. De modo semelhante ao que tem acontecido em outras áreas de investigação, contribui para isso a persistência na produção acadêmica nacional de certa tendência de importação, utilização e "difusão de abordagens conceituais, de problemáticas e de interpretações homogêneas" (Goirand 2010: 460), com base na inserção e circulação de estudantes e pesquisadores entre grupos e redes de pesquisa vinculadas a universidades e instituições dos EUA e da Europa, colaborando, assim, para que os esforços de teorização continuem parciais e limitados (Goirand 2010; Oliveira 2013). "Coladas como etiquetas" aos fenômenos políticos (Queiroz 1976: 18), muitas das ideias, conceitos e resultados vinculados a tais abordagens acabam sendo utilizados com um "viés claramente 
normativo", na medida em que atribui um estatuto negativo ou secundário às relações pessoais no "ordenamento das relações sociais", interpretando-as como "sobrevivência de relações tradicionais" ou, na melhor das hipóteses, como "indício de desenvolvimento incompleto" das instituições políticas (Bezerra 2013: 284).

Nesse sentido, ao seu modo, a produção brasileira faz questão de continuar com uma atitude, ainda muito comum nas ciências sociais, que contribui para que permaneça distante da prática de investigação dos fenômenos políticos a adoção de uma sensibilidade que esteja voltada para a apreensão dos significados que as pessoas estudadas atribuem à sua realidade social e política, assim como a tarefa de tomar como objeto de análise a própria existência de agregados como o Estado, os partidos, os movimentos, etc. (Auyero 2006; Schatz 2009; Latour 2004).

As análises dos partidos políticos centradas no exame dos indivíduos que concorrem ou são escolhidos para a ocupação de cargos eletivos expressa, em certa medida, uma dificuldade muito presente de acesso ao universo dos partidos políticos e de suas dinâmicas concretas de organização e funcionamento. Ainda que o ponto de partida da investigação que está na origem desse trabalho tenha sido também a aplicação de questionários, tal pesquisa foi orientada pela tentativa de dar conta de aspectos e fatos diferenciados a respeito da vida partidária: em primeiro lugar, o foco num tipo de profissional que é quase sempre mencionado nos trabalhos (os burocratas do partido, os auxiliares de candidatos e eleitos), mas que tem recebido pouca atenção da literatura sobre os partidos; em segundo, considerou-se a aplicação do questionário e a realização das entrevistas como formas de acesso ao mundo dos partidos políticos, aos lugares e às temporalidades próprias de tais organizações, ao invés de tratá-las apenas como uma simples técnica de coleta de dados "quantitativos".

Assim, as dificuldades encontradas no processo de negociação e de aplicação dos questionários e realização das entrevistas evidenciaram a importância dos vínculos pessoais com amigos, conhecidos, parentes, etc., para o ingresso e a permanência em tais organizações. Antes de nos defrontarmos com uma dificuldade que é tida como "metodológica", relativa à adequação da técnica ao universo da pesquisa, estávamos diante de um dos aspectos mais constantes das formas de ingresso e de seleção dos funcionários de tais organizações, independente das siglas e ideologias partidárias. Por isso, se o estabelecimento de uma relação de confiança constitui um desafio e uma necessidade premente para o desenvolvimento de qualquer investigação, o olhar reflexivo sobre o conjunto de informações e de "dados" que emergem do processo de aplicação dos questionários salienta a importância de um árduo trabalho de "confecção das redes de confiança" como condição de entrada nesse campo de observação.

Todavia, se os laços e vínculos pessoais constituem um dos ingredientes principais do ingresso como funcionário, e até mesmo como observador, nas 
organizações partidárias, quando se trata de dar conta da grande variação nas formas de atuação profissional dos funcionários, eles não parecem suficientes. Conforme aparece combinada com inserções anteriores em organizações e movimentos sociais e com tipos distintos de experiências profissionais, a atuação como funcionário se apresenta de forma bastante diferenciada. É justamente naqueles casos nos quais os vínculos e os laços com o dirigente são mais intensos e que se combinam com certa distância em relação a inserções e experiências em outras organizações e universos sociais que o peso de tais vínculos aparece como mais forte para a atuação profissional como funcionário do partido. Quando combinado com inserções anteriores em organizações e movimentos sociais e/ou com experiências profissionais anteriores ou simultâneas em outros universos sociais, o laço pessoal que conduziu ao cargo se apresenta como menos decisivo na forma de atuação profissional do funcionário. Tais variações nas formas de atuação não podem ser dissociadas também das dinâmicas de organização e de funcionamento das próprias organizações partidárias. $\mathrm{O}$ fato de o funcionamento de determinado partido estar mais centrado nos líderes, e até mesmo num líder único, ou na participação de instâncias intermediárias, constitui também um ingrediente do peso que tais relações e vínculos irão adquirir no exercício profissional do funcionário. São justamente aquelas situações nas quais a presença de instâncias e líderes intermediários é maior que combinam um tipo de atuação profissional com a inserção em outros tipos de organizações e movimentos sociais.

Esses resultados confirmam a importância de se considerar de forma relacional as condições institucionais e lógicas burocráticas, os laços e vínculos pessoais e os diferentes recursos sociais e formas de atuação profissional nas organizações partidárias. Tal perspectiva constitui um dos principais ingredientes para a ruptura com as abordagens eurocêntricas e normativas dos partidos políticos no Brasil, que atribuem um estatuto menor e secundário aos laços, vínculos e relações pessoais e que, facilmente, desembocam numa abordagem negativa de tais relações. Tal como já tem sido feito a respeito de outros universos sociais (Estado, administração pública, movimentos sociais, etc.), trata-se de demonstrar que relações pessoais, de amizade, etc., antes de se apresentarem como antagônicas e opostas às dinâmicas institucionais, são recursos importantes também para a domesticação das instituições partidárias, na medida em que constituem uma dimensão importante do ingresso e da permanência em tais organizações (Oliveira 2015a, 2017).

Desse modo, ao invés de nos centrarmos na demonstração do peso excessivo e/ou exclusivo das condições e lógicas institucionais ou burocráticas, ou, de maneira oposta, nas relações e laços sociais estabelecidos ao longo das trajetórias individuais, nosso desafio consiste justamente em evidenciar as lógicas complexas e diversificadas de combinação entre as dinâmicas organizacionais e institucionais e as relações, vínculos e laços pessoais. Assim, esse artigo 
evidenciou que a importância das organizações partidárias para o funcionamento da política tem como ingredientes principais tanto os vínculos de parentesco, relações de amizade e camaradagem, obrigações morais, sentimentos de gratidão e reciprocidade, etc., vinculados às formas de dominação direta e pessoal, quanto as lógicas oficiais, as regras institucionais, as prescrições partidárias, etc., que fazem parte da dominação indireta e impessoal. Dar conta de como tais ingredientes se combinam em contextos históricos, políticos e sociais determinados constitui ainda um grande desafio para as ciências sociais.

\section{BIBLIOGRAFIA}

AUYERO, Javier, 1999, “'From the client's point(s) of view': how poor people perceive and evaluate political clientelism”, Theory and Society, 28 (2): 297-334.

AUYERO, Javier, 2006, "Introductory note to politics under the microscope: special issue on political ethnography I", Qualitative Sociology, 29 (3): 257-259.

AUYERO, Javier, 2013, "A rede de solução de problemas do peronismo", Revista Brasileira de Ciência Política, 1 (1): 107-150.

BEAUD, Stéphane, e Florence WEBER, 1998, Guide de l'enquête de terrain. Paris, La Découverte. BENNANI-CHRAÏBI, Mounia, 2010, "Quand négocier l'ouverture du terrain c'est déjà enquêter: obtenir la passation de questionnaires aux congressistes de partis marocains”, Revue Internationale de Politique Comparée, 17 (4): 93-108.

BEZERrA, Marcos Otávio, 1995, Corrupção: Um Estudo sobre Poder Público e Relações Pessoais no Brasil. Rio de Janeiro, Relume-Dumará/ANPOCS.

BEZERRA, Marcos Otávio, 2013, "Representantes políticos, relações pessoais e reputação”, em Ernesto Seidl e Igor G. Grill (orgs.), As Ciências Sociais e os Espaços da Política no Brasil. Rio de Janeiro, Fundação Getulio Vargas, 279-318.

BEZERrA, Marcos Otavio, 2017, "Corrupção e produção do Estado”, Revista Pós: Ciências Sociais, 14 (27): 99-130.

BEZERrA, Marcos Otávio, e Wilson José F. de OLIVEIRA, 2015, “Apresentação”, Tomo: Revista do Programa de Pós-Graduação em Sociologia da UFS, 27: 9-15.

BOLOGNESI, Bruno, 2013, “A seleção de candidaturas no DEM, PMDB, PSDB e PT nas eleições legislativas federais brasileiras de 2010: percepções dos candidatos sobre a formação das listas", Revista de Sociologia e Política, 21 (46): 45-68.

BRAGA, Maria do Socorro S., e Bruno BOLOGNESI, 2013, "Dossiê recrutamento político e seleção de candidatos nas democracias contemporâneas", Revista de Sociologia e Política, 21 (46): 5-9.

BRIQUET, Jean-Louis, 2017, "Pertencimentos locais, experiências cotidianas e práticas políticas: clientelismo e politização na Córsega (séculos XIX e XX)", Revista Pós: Ciências Sociais, 14 (27): 17-32. 
CAmargo, Carla Souza, 2012, Partidos e Grupos Políticos Num Município do Sertão de Pernambuco. São Carlos, Universidade Federal de São Carlos, dissertação de mestrado em Antropologia Social.

COMBES, Hélène, 2009, "Meetings de fin de campagne au Mexique et ethnographie des milieux partisans”, Politix, 22: 149-179.

COMBES, Hélène, e Gabriel VOMMARO, 2012, "Relations clientélaires ou politisation: pour dépasser certaines limites de l'étude du clientélisme”, Cahiers des Amériques Latines, 69: $17-35$.

COMERFORD, John C., e Marcos Otávio BEZERRA, 2013, "Etnografias da política: uma apresentação da coleção Antropologia da Política”, Análise Social, XLVIII (207): 465-489 .

CORADINI, Odaci L., 2001, Em Nome de Quem? Recursos Sociais no Recrutamento de Elites Políticas. Rio de Janeiro, Relume Dumará/UFRJ.

DAlton, Russell J., e Martin P. WATTEnberG (orgs.), 2000, Parties without Partisans: Political Change in Advanced Industrial Democracies. Oxford e Nova Iorque, Oxford University Press.

DANTAS, José I. C., 2002, Eleições em Sergipe (1985-2000). Rio de Janeiro, Tempo Brasileiro.

DANTAS, José I. C., 2004, História de Sergipe República (1889-2000). Rio de Janeiro, Tempo Brasileiro.

DIANI, Mario, e Doug McADAM, 2003, Social Movements and Networks: Relational Approaches to Collective Action. Oxford, Oxford University Press.

FAVRE, Pierre, Olivier FILlIEULE, e Fabien JOBARB, 2007, L'atelier du politiste: théories, actions, réprésentations. Paris, La Découverte/PACTE.

FILLIEULE, Olivier, 2001, "Post scriptum: propositions pour une analyse processuelle de l'engagement individuel", Revue Française de Science Politique, 51 (1): 199-215.

GAXIE, Daniel, 2012, "As lógicas do recrutamento político", Revista Brasileira de Ciência Política, 8: 165-208.

GOIRAND, Camille, 2007, "Pratiques partisanes et loi électorale au Brésil", em Olivier Dabene (org.), Amérique Latine: les élections contre la démocratie?, Paris, Presses de Sciences Po, 41-77.

GOIRAND, Camille, 2010, "Penser les mouvements sociaux d'Amérique Latine: les approches des mobilisations depuis les anneés 1970", Revue Française de Science Politique, 60 (3): 445-466.

GRILL, Igor Gastal, 2008, "Múltiplas dimensões de uma agenda comum de pesquisa: elites, profissionais e lideranças políticas”, em I. G. Grill, E. T. dos Reis e J. Barros Filho, Elites, Profissionais e Lideranças Políticas (RS e MA): Pesquisas Recentes. Maranhão, Edufma (Editora da Universidade Federal do Maranhão), 1 1-26.

KATZ, Richard S., e William J. CROTTY (orgs.), 2006, Handbook of Party Politics. Londres, Thousand Oaks, CA, Sage.

KUSCHNIR, Karina, 2007, "Antropologia e política", Revista Brasileira de Ciências Sociais, 22 (64): 163-67.

LATOUR, Bruno, 2004, "Se falássemos um pouco de política?", Política e Sociedade, 3 (4): $11-40$.

McADAM, Doug, e Ronnelle PAULSEN, 1993, "Specifying the relationship between social ties and activism”, American Journal of Sociology, 99 (3): 640-667.

MICHELS, Robert, 1982, Sociologia dos Partidos Políticos. Brasília, EdUnB. 
MONTAlVÃO, Arivaldo T., 201 1, Recrutamento de Elites Parlamentares em Sergipe: Os Deputados da Arena (1965-1979). São Cristóvão, Universidade Federal de Sergipe, dissertação de mestrado em Sociologia.

MONTALVÃO, Arivaldo T., e Ernesto SEIDL, 2010, “Arena sergipana: trajetórias políticas dos deputados federais", Scientia Plena, 6 (3): 1-12.

NORRIS, Pippa, 2013, "Recrutamento político", Revista de Sociologia e Política, 21 (46): 1 1-32. OfFERLÉ, Michel, 1999, "Professions et profession politique", em Michel Offerlé (org.), La profession politique (XIXe-XXe siècles). Paris, Editions Belin, 7-35.

OLIVEIRA, Wilson José Ferreira de, 2013, "A arte de resistir às palavras: inserção social, engajamento político e militância múltipla”, em E. Seidl e I.G. Grill (orgs.), As Ciências Sociais e os Espaços da Política no Brasil. Rio de Janeiro, Fundação Getulio Vargas, 141-178.

OLIVEIRA, Wilson José Ferreira de, 2015a, "Antropologia, política e etnografia: fronteiras disciplinares e trabalho de campo", em E. Perissinotto e A. Codato (orgs.), Como Estudar Elites. Curitiba, Editora da Universidade Federal do Paraná, 187-214.

OLIVEIRA, Wilson José Ferreira de, 2015b, "Repertórios organizacionais, relações pessoais e atuação profissional em partidos políticos”, Tomo: Revista do Programa de Pós-Graduação em Sociologia da UFS, 27: 291-323.

OLIVEIRA, Wilson José Ferreira de, 2017, "Entre pessoas e instituições: gramáticas nativas e lógicas de composição política”, em J. Comerford, M. O. Bezerra e M. Palmeira (orgs.), Questões e Dimensões da Política. Rio de Janeiro, Papéis Selvagens, 111 -123.

PASSY, Florence, 1998, L'action altruiste. Paris e Genebra, Droz.

PERISSINOTTO, Renato Monseff, e Angel MIRÍADE, 2009, "Caminhos para o parlamento: candidatos e eleitos nas eleições para deputado federal em 2006”, Dados: Revista de Ciências Sociais, 52 (2): 301-333.

PETRARCA, Fernanda Rios, e Wilson José Ferreira de OLIVEIRA, 2016, "Os estudos de elites no Brasil: um ensaio crítico sobre a produção recente”, em E.T. dos Reis e I.G. Grill (orgs.), Estudos sobre Elites Políticas e Culturais, vol. 2. São Luís, Edufma, 141-165.

PETRARCA, Fernanda Rios, e Wilson José Ferreira de OLIVEIRA, 2017, "Parentelas, grupos dirigentes e alianças políticas”, Revista Política \& Sociedade, 16 (37): 191-224.

PHÉLIPPEAU, Eric, 2001, "Sociogênese da profissão política”, em A. Garrigou, e B. Lacroix, Norbert Elias: A Política e a História. São Paulo, Perspectiva, 185-208.

QUEIROZ, Maria Isaura Pereira de, 1976, O Mandonismo Local na Vida Política Brasileira e Outros Ensaios. São Paulo, Alfa-Ômega.

ROCHA, Daniela, 2009, "Militantismo partidário e experiência de poder: o caso do PT no Distrito Federal”, Antropolítica, 23: 67-95.

SCHATZ, Edward (org.), 2009, Political Ethnography: What Immersion Contributes to the Study of Power. Chicago, The University of Chicago Press.

SEIDL, Ernesto, e Igor Gastal GRILL (orgs.), 2013, As Ciências Sociais e os Espaços da Política no Brasil. Rio de Janeiro, Fundação Getulio Vargas.

VERBA, Sidney, Kay L. SCHLOZMAN, e Nancy BURNS, 2005, "Family ties: understanding the intergenerational transmission of political participation”, em A.S. Zuckerman (org.), 2005, The Social Logic of Politics: Personal Networks as Contexts for Political Behavior. Filadélfia, Temple University Press, 95-1 14.

WEBB, Paul, e Robin KOLODNY, 2006, "Professional staff in political parties", em R.S. Katz e W.J. Crotty (orgs.), Handbook of Party Politics. Londres e Thousand Oaks, CA, Sage, 337-347. 
WEBER, Max, 1979, "A política como vocação”, em M. Weber, Ensaios de Sociologia. Rio de Janeiro, Guanabara, 97-153.

ZUCKERMAN, Alan S. (org.), 2005a, The Social Logic of Politics: Personal Networks as Contexts for Political Behavior. Filadélfia, Temple University Press.

ZUCKERMAN, Alan S., 2005b, "Reurning to the social logic of political behavior", em A.S. Zuckerman (org.), The Social Logic of Politics: Personal Networks as Contexts for Political Behavior. Filadélfia, Temple University Press, 3-20.

$\begin{array}{ll}\text { Receção da versão original / Original version } & 2015 / 02 / 23 \\ \text { Receção da versão revista / Revised version } & 2017 / 08 / 15 \\ \text { Aceitação / Accepted } & 2019 / 09 / 23\end{array}$

